\title{
A abordagem de redução de danos em espaços educativos não formais: um estudo qualitativo no estado do Rio de Janeiro, Brasil
}

\author{
Kátia Mendes de Souza ${ }^{1}$ \\ Simone Monteiro
}

SOUZA, K.M.; MONTEIRO, S. Harm reduction approach in non-formal educational situations: a qualitative study in the state of Rio de Janeiro. Interface - Comunic., Saude, Educ., v.15, n.38, p.833-44, jul./set. 2011.

This paper discusses the contributions of the harm reduction approach towards educational practices relating to health and drugs, in non-formal situations, from an analysis on the theoretical and methodological fundamentals and activities of a project developed by the Oswaldo Cruz Institute, among educators from nongovernmental organizations in Rio de Janeiro, from 2006 to 2007. Guided by a qualitative approach, this study analyzed the educators' professional practices, the paths taken and the institutional context, by means of document analysis, interviews and direct observations. The findings revealed that the educators had appropriated and given new meaning to the concepts dealt with in the project, in relation to education for autonomy, harm reduction and vulnerability, guided by a dialogical and critical approach towards the knowledge construction process.

Keywords: Health education. Drugs. Harm reduction. Methodology. Educator training.
Este artigo discute as contribuições da abordagem de redução de danos para a prática educativa em saúde e drogas, em espaços não formais, a partir da análise dos fundamentos teórico-metodológicos e das atividades de um projeto desenvolvido pelo Instituto Oswaldo Cruz, com educadores de organizações não governamentais do estado do Rio de Janeiro, Brasil, de 2006 a 2007.

Orientado por uma abordagem qualitativa, o estudo analisou a trajetória e as práticas profissionais de educadores e o contexto institucional, por meio da análise documental, de entrevistas e observações diretas. Os achados revelaram que houve apropriação e ressignificação, pelos educadores, dos conceitos abordados no projeto relativos à educação para autonomia, redução de danos e vulnerabilidade, orientados por uma abordagem dialógica e crítica do processo de construção do conhecimento.

Palavras-chave: Educação em Saúde. Drogas. Redução de danos. Metodologia. Formação de educadores.
"Elaborado com base em Souza (2010); projeto aprovado pelo Comitê de Ética em Pesquisa da Escola Nacional de Saúde Pública Sérgio Arouca. 1,2 Laboratório de Educação em Ambiente e Saúde, Instituto Oswaldo Cruz, Fundação Oswaldo Cruz. Av. Brasil, 4365, Pavilhão Lauro Travassos, sala 22. Rio de Janeiro, RJ, Brasil. 21.045-900. mendesdesouzaktia@ gmail.com 


\section{Introdução}

Inúmeros estudos quantitativos revelam um expressivo aumento de consumo e dos danos causados pelo uso abusivo de drogas lícitas e ilícitas em faixas etárias cada vez mais precoces no Brasil (Galduróz et al., 2004; Paulilo, Jeolás, 2000; Guerchman, 1998; Bemfam, 1992).

Em termos das ações de controle e prevenção/educação do uso indevido de drogas, os estudos apontam para as limitações e insucesso da abordagem tradicional de negação total ao uso de drogas, conhecida como "Guerra às Drogas". Argumenta-se que as ações educativas sobre saúde e drogas devem ser planejadas junto ao público-alvo, combinando os interesses e conhecimentos de educadores e educandos e as necessidades e potencialidades da realidade local. A contextualização das ações educativas confere mais sentido e valor para os envolvidos no programa, pois procura considerar as características de cada comunidade relativas à diversidade de usuários, aos tipos de drogas disponíveis na região e ao contexto cultural e socioeconômico das diversas realidades. Tais aspectos possibilitam a criação de estratégias mais adequadas e pertinentes a cada realidade (Santos, Soares, Campos, 2010; Soares et al., 2009; Martini, Furegato, 2008; Feffermann, Figueiredo, 2006; Canoletti, Soares, 2005; Laranjo, 2004; Soares, Jacobi, 2000; Carlini-Cotrim, 1998).

No contexto das reflexões assinaladas, o Ministério da Saúde adotou, como forma inovadora para as políticas de saúde, a abordagem de redução de danos, que se define pela busca de uma diminuição dos níveis de danos relacionados ao uso de drogas, tanto para o usuário quanto para a sociedade de forma geral. Este conceito ganhou visibilidade a partir dos programas de controle do HIV/AIDS voltados para usuários de drogas injetáveis:

\footnotetext{
As ações de redução de danos constituem um conjunto de medidas de saúde pública voltadas para minimizar as consequências adversas do uso de drogas. O princípio fundamental que orienta $[\mathrm{a} \mathrm{RD}$ ] é o respeito à lei e a liberdade de escolha, à medida que os estudos e a experiência dos serviços demonstram que muitos usuários, por vezes, não conseguem ou não querem deixar de usar drogas e, mesmo esses, precisam ter o risco de infecção pelo HIV e hepatite minimizados. (Brasil, 2001a, p.12)
}

O conceito de redução de danos resulta numa crítica à proposta da abstinência como discurso único e verdadeiro na prevenção ao uso indevido de drogas (Fonseca, 2005; Figueiredo, 2002). Nesta direção, o uso ou abuso de drogas não constitui um fenômeno exclusivamente individual, mas se relaciona à drogalidade do indivíduo (Acselrad, 2005). Esta é entendida como as relações que cada pessoa estabelece com as drogas, mediada por fatores diversos, que incluem as dimensões: biológica, psicológica, familiar, socioeconômica e cultural, contrapondo-se a uma visão tradicional e repressiva que reforça preconceitos.

Apesar de ainda representar uma novidade para muitos profissionais de educação e saúde e gerar polêmicas por ter um caráter inovador no enfrentamento do uso indevido de drogas, o conceito de Redução de Danos tem sua origem nos anos de 1920 na Inglaterra. Nesse período, uma comissão de médicos ingleses - Comitê Rollerston - concluiu que poderia ser ocasionalmente necessário manter uma pessoa utilizando drogas para ajudá-la a levar uma vida mais produtiva. Em 1950, no Canadá, uma província se torna a primeira jurisdição na América do Norte a adotar a manutenção de metadona para reduzir os danos associados ao uso de heroína. Nos anos de 1960, o tratamento com substituição por metadona passa a ser adotado em outras localidades da América do Norte (Hilton et al., 2000).

As estratégias de Redução de Danos vêm sendo implantadas no Brasil através dos Programas ou Projetos de Redução de Danos (PRD), que contemplam um conjunto de ações desenvolvidas, em campo, por redutores de danos, tais como: distribuição de seringas, atividades de informaç̧ão, educação e comunicação (IEC), aconselhamento, encaminhamento, vacinação contra hepatite B e outras ações preventivas. A estruturação deste trabalho se deu a partir de estudos realizados, como o "Projeto AJUDE BRASIL" (Caiaffa, 2001), que identificou o perfil dos usuários de drogas injetáveis participantes de cinco programas de redução de danos apoiados pela Coordenação Nacional de DST/Aids, (atualmente denominada Departamento de DST, Aids e hepatites virais); bem como o Estudo 
Multicêntrico da Organização Mundial de Saúde - fase II (Brasil, 2001b), que reavaliou as características dos usuários de drogas no Rio de Janeiro, Salvador e Baixada Santista, e identificou as respectivas taxas de infecção pelo HIV e os vírus das hepatites B e C. Grande parte da mobilização por este trabalho se deve às organizações criadas após a "IX Conferência Internacional de Redução de Danos", que ocorreu em São Paulo, em 1998. A Associação Paulista de Redutores de Danos (APRENDA) e a Associação Brasileira de Redutores de Danos (ABORDA) são constituídas por: redutores de danos, usuários de drogas ou não, técnicos de diversas áreas, e pessoas comprometidas com as questões de drogas-HIV-cidadania.

Santos, Soares e Campos (2010) constatam a existência de diferentes concepções de redução de danos adotadas na literatura, advindas dos conceitos de sujeitos e objetos adotados pelos diversos autores. Como forma de não incorrer em pragmatismos, setorizando as relações entre objetos e sujeitos, conforme recomendam as autoras, a concepção de redução de danos apresentada neste artigo baseia-se numa compreensão mais global e crítica sobre a realidade histórica e social:
A partir da Saúde Coletiva, é possível observar a preocupação em compreender a complexidade que cerca o fenômeno das substâncias psicoativas na sociedade contemporânea, e a constituição da RD, como um novo paradigma, requer um arcabouço teórico-metodológico amplo e interdisciplinar que inclua os saberes de diversas áreas para que não fique restrita ao excesso de pragmatismo e a compreensões desvinculadas e desconectadas da totalidade social. (Santos, Soares, Campos, 2010, p.1007)

A literatura nacional e internacional associa a abordagem de Redução de Danos à formulação de estratégias educativas, onde educadores e educandos necessitam reconhecer os diferentes aspectos envolvidos no processo do uso de drogas, quais sejam: o tipo, a quantidade e a frequência da droga consumida, e o contexto social, cultural, histórico e jurídico do uso. Nestas estratégias, são considerados: as relações entre consumo e formação de rede social, experiências sexuais, projetos de vida, o processo saúde e doença, as situações de violência, entre outros (Laranjo, 2004; Soares, Jacobi, 2000; Carlini-Cotrim, 1998; Paglia, Room, 1998).

A maior parte dos estudos citados investiga a perspectiva da redução de danos no âmbito escolar formal. O presente artigo objetiva analisar a prática educativa em saúde e drogas em espaços não formais, no caso, organizações não governamentais com práticas de educação em saúde no âmbito comunitário. Tem-se o propósito de identificar em que medida a formação dos profissionais sobre saúde, educação e drogas, somada à trajetória profissional e ao contexto de atuação profissional, contribuíram para: 1) a compreensão dos participantes sobre as diferentes dimensões históricas, socioculturais e econômicas associadas ao uso devido e indevido de drogas lícitas e ilícitas; 2) estimular a promoção de ações educativas embasadas em propostas problematizadoras e transformadoras; 3 ) fomentar o estabelecimento de uma rede local entre os participantes e demais organizações, garantindo a sustentabilidade e a continuidade das ações, por meio da implementação de estratégias integradas. Canoletti e Soares (2005) ressaltam a importância e, ao mesmo tempo, a escassez da explicitação do processo formal de avaliação em projetos de prevenção, que sinalizem os resultados atingidos a médio e longo prazo. No presente artigo são apresentados e analisados os resultados após cerca de dois anos de realização do projeto.

Por meio deste enfoque, objetiva-se avançar na discussão sobre o profundo hiato entre a teoria e a prática no campo da educação em saúde, expresso pela constatação de que as reorientações, resultantes das reflexões teóricas e metodológicas nessa área, não vêm sendo traduzidas ou operacionalizadas, nas práticas educativas, pelos educadores (Gazzinelli et al., 2005).

\section{Metodologia}

O desenho metodológico baseou-se no entendimento dos significados produzidos no âmbito cultural, atualizados nas relações entre os sujeitos, dialogando com modelos socialmente compartilhados 
(Víctora, Knauth, Hassen, 2000; Geertz, 1989). Nesse marco teórico, a trajetória pessoal e profissional dos educadores, incluindo a formação, associada ao contexto institucional, ganhou destaque na análise das repercussões de um projeto sobre saúde, educação e drogas. Este projeto - "Saúde e Drogas: Desenvolvimento e Avaliação de Ações Educativas em Programas Sociais" - doravante chamado Saúde e Drogas, foi desenvolvido por uma instância pública de produção de conhecimento científico, a Fiocruz, especificamente pelo Laboratório de Educação em Ambiente e Saúde (LEAS) do Instituto Oswaldo Cruz (IOC) ${ }^{3}$, com o apoio do Instituto C\&A de Desenvolvimento Social. O público-alvo desta experiência foram educadores de quatorze organizações não governamentais que atuavam na educação não formal de adolescentes e jovens no Estado do Rio de Janeiro. Desenvolvido no período de fevereiro de 2006 a julho de 2007, seu objetivo foi contribuir para o desenvolvimento e avaliação de programas educativos sobre saúde, drogas e temas afins.

Para fins deste artigo, foram analisados dados secundários, na forma de relatórios e registros, das ações desenvolvidas ao longo da formação dos educadores. $\mathrm{Na}$ leitura destes documentos, buscou-se identificar o nível de adequação do plano de ação, expresso pela clareza, objetividade e coerência com o referencial teórico, e o nível de integração com a instituição, expresso pelo grau de receptividade para a proposta e pelo grau de sustentabilidade e continuidade das ações. Este exame inicial permitiu a seleção de cinco, das quatorze instituições que faziam parte do projeto original. Além da análise documental, foram realizadas entrevistas semiestruturadas e observações diretas. Foi entrevistado um educador de cada uma das cinco instituições selecionadas, totalizando cinco educadores que, além de terem participado do projeto, permaneciam na instituição dois anos após sua finalização. As entrevistas foram antecedidas de uma apresentação da equipe de trabalho, espaço físico e forma de organização dos processos de trabalho de cada uma das instituições. Este processo propiciou o acesso ao ambiente e à organização do cotidiano institucional. Foi realizada uma observação direta de uma reunião de equipe e de algumas atividades institucionais.

Os dados das entrevistas e das observações foram organizados por meio da identificação de núcleos de sentido e da categorização temática (Minayo, 2007), e articulados aos achados da análise documental. A integração das diferentes fontes teve o propósito de discutir a lógica de significados relacionados à prática educativa na interface entre redução de danos e drogalidade, entendendo que o projeto sobre saúde, educação e drogas havia oferecido um repertório de conceitos, perspectivas e instrumentos que rompiam com um modelo hegemônico de abordagem às drogas. Para manter o sigilo, os educadores foram identificados através de nomes fictícios.

\section{Resultados e discussão}

\section{Fundamentos teórico-metodológicos e ações do projeto Saúde e Drogas}

A análise documental possibilitou o acesso aos fundamentos teórico-metodológicos do projeto Saúde e Drogas, revelando uma formação orientada para práticas educativas pautadas nos conceitos de autonomia, redução de danos e vulnerabilidade. Nestes marcos, comparece uma filosofia problematizadora com uma abordagem dialógica e crítica do processo de construção do conhecimento.

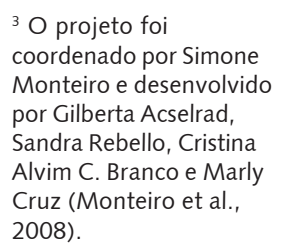


A articulação dessa abordagem educativa ao conceito de redução de danos resulta numa crítica à proposta da abstinência como discurso único e verdadeiro na prevenção ao uso indevido de drogas. Ao ter o objetivo de esclarecer e dialogar sobre os efeitos danosos relacionados ao uso de drogas, a educação para a autonomia, considera o direito e o respeito à liberdade de escolha da cada indivíduo. Dentro desta perspectiva, critica a importância dada pela sociedade apenas às drogas de uso ilícito, que reforça o estigma dos usuários e a permissividade aos danos decorrentes do uso de drogas lícitas (Acselrad, 2005). Tal perspectiva se coaduna com os pressupostos do conceito de vulnerabilidade, que considera a interação de fatores de natureza biológica, epidemiológica, social e cultural para a proteção ou exposição a determinado dano à saúde (Ayres et al., 2006).

Orientada pela articulação entre os fundamentos dos conceitos de educação para autonomia, redução de danos e vulnerabilidade, a equipe responsável pela formação priorizou a divulgação de conhecimentos e o estímulo ao debate sobre as dimensões histórica, epidemiológica, jurídica, sociocultural e econômica acerca das drogas, diferenciando-se da visão preconceituosa e alarmista presente em propostas educativas e nos discursos acerca do tema.

Tendo em vista que a vulnerabilidade e a exposição aos danos relacionados ao uso de drogas são específicas de cada contexto social, as ações educativas previstas foram construídas com base nas trajetórias e inserção profissional dos educadores, objetivando ações contextualizadas e baseadas na noção de corresponsabilidade.

Nota-se, a partir dos documentos e arquivos analisados, que o projeto Saúde e Drogas teve, como forma de acesso às instituições, uma abordagem participativa e não normativa. A utilização de uma carta-convite como instrumento para oferecer a proposta ilustra esta perspectiva. Das 23 instituições não governamentais com parcerias com o Instituto C\&A, em fevereiro de 2006, 14 responderam ao convite e participaram da $1^{\mathrm{a}}$ oficina de formação, demonstrando o interesse pela formação.

Destaca-se, ainda, como estratégia metodológica, a realização de três oficinas com intervalos de três a seis meses, com o oferecimento e discussão de conteúdos para a elaboração de planos de ação e a entrega de um kit de materiais educativos e referências bibliográficas. Com o objetivo de orientar o processo e implantação dos planos de ação e a inserção das ações de prevenção ao uso abusivo de drogas nas instituições, após a primeira oficina, foram realizadas visitas de acompanhamento. As oficinas que se seguiram propiciaram a apresentação dos trabalhos desenvolvidos a partir dos planos de ação institucionais, com consequente intercâmbio de experiências entre os participantes.

O intervalo entre as oficinas e o acompanhamento permitiu que os educadores refletissem sobre a formação oferecida e suas repercussões nas experiências cotidianas, fomentando um diálogo sobre as articulações entre a teoria e a prática. O exercício de apresentação de suas propostas e ações estimulou a sistematização e verbalização da prática, favorecendo o intercâmbio de visões e a reelaboração coletiva dos projetos locais. Ressalta-se que, ao longo de todo o Projeto, foram realizados exercícios de avaliação processual onde os participantes expressavam-se, tanto pela escrita quanto verbalmente, sobre as atividades desenvolvidas, contribuindo para possíveis reorientações das ações.

Como última etapa da metodologia, destaca-se a realização do Seminário "Saúde, Drogas e Educação", que permitiu uma análise sobre o valor atribuído pelo projeto à dimensão coletiva de construção de conhecimento voltado para o educador que atua na abordagem às drogas. A devolução de todo o processo se deu na forma de uma publicação (Monteiro et al., 2008), visando: socializar o conhecimento adquirido ao longo da experiência, estimular o desenvolvimento de novas ações, e valorizar a perspectiva dos educadores na produção de conhecimentos.

\section{Análise das trajetórias profissionais nos diferentes contextos institucionais}

A caracterização do perfil profissional de cada educador permitiu revelar aspectos da trajetória profissional e identificar o conhecimento prévio, os interesses e a experiência dos educadores sobre as drogas. Ademais, possibilitou uma melhor compreensão sobre os significados dos conceitos relacionados ao tema de uma forma geral, na relação com os pressupostos e conceitos oferecidos pelo Projeto.

Situando os sujeitos no seu contexto cultural, sobretudo no que se refere as suas trajetórias profissionais, assinala-se que os cinco entrevistados possuíam cursos de graduação na área de ciências 
humanas, tendo dois deles cursos de Mestrado. Esta descrição nos permite inferir que este perfil de formação contribui para uma sintonia entre as propostas do projeto e a adesão a uma visão ampliada sobre a relação entre juventude e drogas. Formações anteriores nas áreas de droga dependência e produção de audiovisual acentuam o interesse para reunir, a formação técnica, a uma formação geral afinada com a área social, cultural e humana. Destaca-se, ainda, que o tempo de atuação dos educadores na área de educação em saúde era superior a dez anos, e o período de inserção na instituição atual variou entre três e dez anos. Em se tratando de um vínculo com organizações não governamentais, que tendem a ter certa rotatividade de profissionais em função da variação de projetos e apoios financeiros, pode-se considerar que o período descrito é um tempo significativo de adaptação, estabilidade e vínculo institucional.

As trajetórias profissionais construídas, ou seja, os diferentes conhecimentos e experiências vivenciadas contribuíram para processos criativos na aproximação com os jovens. Isto foi ilustrado por duas educadoras, que elaboraram, de forma coletiva, histórias em quadrinhos e um filme, como estratégias lúdicas de abordagem da temática das drogas. Estas trajetórias encontraram um contexto institucional que favoreceu o desenvolvimento das propostas educativas.

Neste sentido, as condições de trabalho dos educadores, os temas desenvolvidos e o grau de espaço e de autonomia dado pela instituição para criar e incluir novas temáticas, no caso, as drogas, configuramse como aspectos importantes para a análise. As instituições têm um tempo de existência que variou entre nove e 29 anos, e competências reconhecidas nas áreas de educação, saúde, arte-educação, produção teatral, audiovisual e inclusão digital. Quer dizer, atuam em diferentes campos e têm dinâmicas de funcionamento específicas. De forma geral, realizam ações voltadas à prevenção, educação, desenvolvimento comunitário e direitos humanos, mas diferenciam-se no desenvolvimento de temáticas: saúde, gênero, prevenção de doenças sexualmente transmissíveis/Síndrome da Imunodeficiência Adquirida, violência, drogas, arte, música, dança, teatro, meio ambiente, cidadania, informática e produção de vídeos. Algumas realizam trabalhos de pesquisas e/ou contato direto com o público-alvo, na comunidade, nas escolas e em hospitais. Os jovens são o público-alvo para a maioria destas instituições, sendo que algumas organizações também envolvem a família dos jovens nas atividades.

Quanto à sustentabilidade, algumas instituições baseiam-se em trabalho voluntário e contam apenas com doações de pessoas físicas, enquanto outras possuem projetos de mais longo prazo, com pessoas contratadas, uma ampla rede de parceiros e financiamento de instituições nacionais e internacionais. Em suma, os diferentes contextos institucionais, funções desempenhadas e tempos de inserção revelaram variações nos graus de autonomia para a implementação de propostas e ações dos educadores.

Os educadores que participaram das oficinas se tornaram referência para o trabalho, mas, em algumas instituições, foram incluídos outros educadores, coordenadores e os próprios jovens na corresponsabilização pelas ações. O perfil profissional, envolvendo a formação e a experiência do educador, e a receptividade do contexto institucional, somada ao apoio e sustentabilidade das ações, foram condições decisivas para o bom desenvolvimento dos planos de ação propostos. O contexto institucional representa a base onde são construídos os processos de trabalho do educador. Se este dispõe de um ambiente acolhedor, com boas relações interpessoais, de tempo suficiente e de condições materiais para planejar, propor, desenvolver, sistematizar e avaliar as ações educativas, ele se sente mais seguro para implementar ações criativas e inovadoras. Como a abordagem de redução de danos não é uma linha hegemônica em nossa sociedade, a ausência de um contexto institucional favorável compromete a aproximação e a discussão sobre o tema.

Embora o curso de formação desenvolvido pelo projeto Saúde e Drogas tenha incentivado a constituição de uma rede entre as instituições participantes, os educadores entrevistados indicaram que não houve uma aproximação entre as instituições após a finalização do projeto. Igualmente, não foi observado um envolvimento das famílias das populações atendidas pelas instituições nas atividades propostas. A identificação do não-estabelecimento da rede social local comprometeu, em parte, a sustentabilidade e a continuidade das ações.

Observa-se que a abordagem da redução de danos é um tema novo e polêmico na sociedade de forma geral, e que há poucos projetos com ações e financiamento nesta linha com os quais as instituições participantes no projeto Saúde e Drogas pudessem se articular e interagir. 


\section{Os significados produzidos pelos educadores sobre redução de danos}

Para alguns participantes, que relataram experiências de diferentes tipos de uso, abuso e dependência química entre seus familiares, o curso teve um sentido ainda mais amplo, por tocar em aspectos da vida pessoal relacionados a vivências emocionalmente dolorosas e difíceis.

Além das experiências familiares, foi interessante observar a relevância e o sentido que o conceito de redução de danos, bem articulado com o de educação para autonomia, passou a ocupar na vida pessoal e profissional de cada educador. Ainda que com diferentes formulações, as opiniões dos participantes reforçam a necessidade da ampliação desta linha de debate para educadores, jovens, famílias e para a sociedade de forma geral. Nesta direção, Rosa fez uma interessante comparação entre a abordagem centrada na prevenção e a aplicação do conceito de redução de danos na prática educativa:

\footnotetext{
“Pra mim, a redução de danos parte do pressuposto de que a gente está imerso, é autor de relações e nestas relações a gente pode encontrar maneiras de promover saúde nestas relações, o que difere da lógica da prevenção, que é uma lógica quase que puritanista, de que a gente pode supor que estas relações vão deixar de existir, quando elas não vão porque é condição humana que estas relações existam. [...]. É lidar com o que existe de fato, e como é que a gente pode lidar com o que existe de fato, acho que o "de fato" pra mim tem haver com esta dimensão da realidade e não da fantasia: "Os meninos não vão usar." Eles vão, não, eles já estão (usando drogas)".
}

O trecho anterior nos remete às críticas à perspectiva preventiva, pautada no modelo biomédico, na qual o corpo humano é analisado de forma fragmentada, desconectado da rede de relações que compõe o sentido de sua vida (Czeresnia, 2003). Destaca-se ainda, neste modelo, a redução do sujeito ao objeto da intervenção, com sua concomitante perda de autonomia.

A perspectiva de redução de danos vai ao encontro de uma abordagem democrática sobre a saúde. Nesta direção, José aponta, na abordagem educativa adotada pelo projeto, a possibilidade de uma democratização dos conhecimentos e a sua tomada de responsabilidade como educador de jovens:

\footnotetext{
“Deve haver esclarecimento e este é o papel da escola. A família não tem este suporte. É liberdade de escolha, ele tem esse direito e tem a liberdade de usar de experimentar, ter acesso, ser usuário. [...] Educação para autonomia, para mim, é dar condições, embasar, ter ferramentas, e que ele possa construir e ser responsável por ele e por aquilo que está a sua volta".
}

A abordagem de redução de danos pressupõe o direito ao acesso a conhecimentos científicos atualizados, mas evita interpretações ou julgamentos próprios; reconhece o educando como cidadão que tem o direito de receber informações e orientações e que irá decidir por si. Nesta linha, a saúde é compreendida pela construção e capacidade de escolhas dos atores sociais envolvidos no processo. Reforçando o conceito de construção de autonomia, Freire (1996) defende que só há aprendizado quando o ser humano está na condição de sujeito, e não de objeto da ação educativa. Cada sujeito possui sua história de vida e questões de saúde, e estas estão sempre relacionadas à coletividade.

Para Margarida, o conceito trouxe uma "leveza para o olhar", tirando o peso da responsabilidade exclusiva do usuário e facilitando a compreensão das influências do contexto social e cultural nas escolhas dos indivíduos. Esta abordagem aproxima o educador para tratar do tema com usuários:

\footnotetext{
“Eu entendi que é fazer a vida deste usuário um pouco mais fácil, um pouco mais simples, e colocá-lo no lugar, nem da vítima e nem do errado, nem do certo. Fazê-lo entender que... sim, ele está usando, mas o que a gente faz pra não ser tão avassalador? Tem a ver com a valorização dessa pessoa, porque eu acho geralmente é tratado com muito preconceito. Eu sei que é muito difícil, não é fácil e tem a ver com incluí-lo também, responsabilizá-lo pra estar melhor e com ajuda da comunidade. Eu entendi desta forma: ele tem responsabilidade,
} 
mas o entorno também tem, e ele pode sair deste lugar da culpa. Porque eu acho que isso é muito ruim, que dificulta muito".

Nas análises acerca dos efeitos negativos das campanhas pela abstinência de drogas, discute-se como esta linha culpabiliza o indivíduo por problemas macrossociais. Não se discutem as implicações do fortalecimento da sociedade de consumo pela mídia e do modelo econômico neoliberal, que estimulam o desejo de consumo pelos segmentos juvenis das diversas classes sociais, com vistas à aceitação social (Martini, Furegato, 2008; Moreira, Silveira, Andreoli, 2006).

A observação da entrevistada, seguida da analise anterior, é concordante com a pesquisa sobre o projeto "Escola é Vida", desenvolvido nas unidades públicas estaduais de ensino de São Paulo, centrado na redução de danos. A pesquisa apontou que professores e estudantes, sentindo-se participantes e mobilizados, passaram a ser mais tolerantes e solidários com relação ao uso de drogas (Soares, Jacobi, 2000). A criação de espaços de discussão sobre redução de danos mostra-se como alternativa para o enfrentamento de processos de culpabilização dos indivíduos.

Assim, a abordagem de redução da vulnerabilidade aos danos relacionados ao uso de drogas se configura num processo dinâmico, multifacetado e determinado por diversos fatores, rompendo com a responsabilização do indivíduo. Este processo não prescinde da necessidade da superação dos obstáculos de ordem material, cultural e política, que poderiam manter o indivíduo vulnerável, ainda que esclarecido.

Para Ana, a proposta inovadora da formação oportunizou a revisão e atualização sobre o tema drogas para uma campanha comunitária com jovens de uma escola estadual, cujo produto final seria uma radionovela e uma história em quadrinhos, ambas produzidas pelos alunos. Ana utilizou uma metodologia participativa, com momentos de discussão sobre os temas e a divisão em grupos de trabalho para a produção de textos, desenhos, encenação. A campanha culminou com uma festa na escola e o lançamento de um material em áudio (compact disc) dos materiais produzidos. Estes materiais apresentam uma abertura, ao invés de proporem prescrições de comportamentos, ideais ou soluções finais para os assuntos abordados. A continuidade das ações foi favorecida pela possibilidade de execução do compact disc em ambientes comuns aos jovens e seus familiares, como salões de beleza e outros locais de convívio, e pela praticidade e rapidez de leitura dos quadrinhos, permitindo releituras e novas discussões sobre o tema.

Seguindo, igualmente, a ênfase interdisciplinar proposta pela redução de danos, Rosa criou uma estratégia para abordar o fenômeno das drogas de forma vivencial e prazerosa, diferenciada das formações muito teóricas e racionais já conhecidas sobre o tema, oferecendo uma formação continuada para os vinte e cinco educadores de sua equipe. Na ocasião da entrevista, um dos grupos de educadores estava desenvolvendo um projeto de produção de um filme sobre tradições das famílias dos jovens, sendo a maioria do Nordeste. Após as pesquisas e elaboração do roteiro, surgiu o tema do cangaço. Ela cita que as referências do curso têm voltado frequentemente, pois os jovens fizeram uma associação direta com o tráfico, muito presente em suas comunidades:

\footnotetext{
"Ontem apareceu com muita força a questão do tráfico, eles relacionando o cangaceiro com o traficante, e começando a contar todas as relações que eles conhecem, que eles tem, que eles veem. [...] Não era uma aula sobre tráfico de drogas; não foi um pressuposto: "Não! O tráfico é ruim! Não faça uso! Não lide com ele!" Como se ele não existisse...Completamente diferente de quando você cria uma ambiência e uma relação com estes meninos a ponto de, num trabalho que fala sobre o cangaço, quando eles estão filmando uma história que eles mesmos criaram, que tem haver com o cangaceiro, e na feitura do filme e este tema do traficante de onde ele mora aparece, carregado das histórias, dos sentidos".
}

Por meio desta metodologia dialogada, foi possível perceber, positivamente, a proposta dos projetos desenvolvidos há anos pela instituição onde Rosa atua. No diário de bordo dos educadores, são registradas as suas experiências e a fala dos jovens, onde se identifica uma prática de educação problematizadora: 


\begin{abstract}
"Pelo fato de a gente trabalhar com a formação deste sujeito, como alguém que precisa se reconhecer autor de sua própria história nesta relação com este mundo...todo esse investimento que a gente faz, desde muito pequeno, pra esta percepção de: Quem sou eu? Quem sou eu nesta relação com o outro? Quem é esse outro? Que lugar é esse que a gente tá? Como estes sujeitos se fortalecem, não como sujeitos isolados, mas como sujeitos que só são porque estão em relação com estes outros e com este contexto. Sujeito que tem condições de fazer escolhas, que tem condições de se posicionar com autonomia frente a algumas questões, que tem desejo de se implicar com algumas transformações que se fazem necessárias para o bem de todos".
\end{abstract}

Esta proposta educativa crítica se mostra como uma superação do amedrontamento sobre o uso de drogas evidenciado na abordagem tradicional. A abordagem repressiva pode despertar a curiosidade e o desejo de experimentação, sem estimular a capacidade de percepção mais cuidadosa sobre o corpo e a saúde. O clima de temor e mistério sobre as drogas deixa o jovem mais vulnerável e desprovido de informações consistentes acerca de cada tipo e efeito de droga. Os calmantes, os remédios de emagrecimento e anabolizantes, por exemplo, vêm tendo um consumo abusivo entre jovens e adolescentes (Figueiredo, 2002).

A articulação dessa abordagem educativa ao conceito de redução de danos evidencia a necessidade de se elaborar um discurso ligado à drogalidade, ou seja, sobre as relações que os indivíduos estabelecem com as drogas, que permita transferir a ênfase do enfoque da droga em si e das implicações do consumo de forma isolada, para uma perspectiva centrada nas relações estabelecidas entre o indivíduo e as necessidades e estímulos sociais ao uso de drogas. Dentro desta perspectiva, critica a importância dada pela sociedade apenas às drogas de uso ilícito, que reforça o estigma dos usuários e a permissividade aos danos decorrentes do uso de drogas lícitas (Acselrad, 2005).

Metodologia e resultados semelhantes foram descritos por Soares et al. (2009), a partir da experiência de oficinas de instrumentalização de trabalhadores de instituições sociais no território de abrangência de uma Unidade Básica de Saúde. Foi verificado que a criação de espaços dialógicos sobre as drogas mostrou-se "instrumento potente para que os sujeitos - agentes e co-produtores do processo educativo - participem com a finalidade de transformar a práxis reiterativa em práxis criativa" (p.196), produzindo uma alteração qualitativa da prática social.

\title{
Conclusões
}

O processo de aprimoramento das estratégias de redução de danos, tanto no Brasil como em outros países, nos leva a concluir que o uso de drogas não deve ser tratado de forma isolada, mas como um dos muitos danos a serem reduzidos na população, por meio de intervenções mais dignas e humanas, promovidas pela sociedade civil organizada e por políticas governamentais no campo da Saúde Pública, preferencialmente, de forma conjugada.

A redução de danos como conceito parece necessitar, para sua divulgação, de metodologias ativas de ensino-aprendizagem que permitam rever representações culturais arraigadas sobre as drogas. No caso analisado, a utilização de estratégias pedagógicas participativas no desenvolvimento de um projeto sobre saúde e drogas com educadores de organizações não governamentais permitiu a desconstrução de valores e a revisão de outros. Pode-se constatar que a metodologia utilizada pelo projeto baseou-se na construção compartilhada do conhecimento, ou seja, implicou: "um processo comunicacional e pedagógico entre sujeitos de saberes diferentes, convivendo em situações de interação e cooperação, que envolve o relacionamento entre pessoas ou grupos com experiências diversas, interesses, desejos, motivações coletivas" (Carvalho, Acioli, Stotz, 2001, p.103).

A temporalidade, ou seja, o reconhecimento do tempo como processo necessário à elaboração do conteúdo, fez parte da metodologia da experiência analisada neste artigo. Este aspecto parece ter favorecido o incremento do diálogo e a revisão de posturas pessoais e profissionais por parte dos sujeitos participantes. A análise empreendida na incorporação do conceito de redução de danos na 
prática educativa não formal refere-se tanto à consideração das trajetórias pessoal/profissional construídas quanto ao contexto institucional, que podem favorecer ou dificultar as abordagens das drogas pela perspectiva da redução de danos.

Canoletti e Soares (2005) identificam que a maior parte da produção científica sobre programas de prevenção às drogas, de 1991 a 2001, encontra-se numa categoria transitória entre o modelo hegemônico de guerra às drogas e um novo modelo em construção, ligado à redução de danos. Ademais, esta produção está relacionada a um estágio de experimentação, mais com a apresentação de orientações e propostas do que a descrição do desenvolvimento de programas de prevenção propriamente ditos. Este estudo revela, portanto, um avanço na aproximação entre teoria e práticas neste campo.

Um possível limite de nossa análise refere-se à necessidade de se investigarem experiências com o conceito de redução de danos aplicadas em realidades de educação não formal, onde os sujeitos responsáveis pelo trabalho não possuam nível de escolaridade e formação que retratem acúmulos críticos sobre cultura e sociedade. E que, além disso, não tenham uma estrutura organizacional tão favorável à absorção dos conteúdos sobre redução de danos.

\section{Colaboradores}

Kátia Mendes de Souza foi responsável pela coleta de dados, análise e redação do trabalho. Simone Monteiro participou da análise, redação e revisão final do artigo.

\section{Agradecimentos}

Gostaríamos de agradecer a todos os educadores que participaram do estudo, e à equipe do projeto Saúde e Drogas, pelo acesso aos dados sistematizados.

\section{Referências}

ACSELRAD, G. A educação para autonomia: construindo um discurso democrático sobre as drogas. In: ACSELRAD, G. (Org.). Avessos do prazer: drogas, Aids e direitos humanos. Rio de Janeiro: Ed. Fiocruz, 2005. p.183-212.

AYRES, J.R.C.M. et al. Risco, vulnerabilidade e práticas de prevenção e promoção da saúde. In: CAMPOS, G.W.S. et al. (Orgs.). Tratado de saúde coletiva. São Paulo: Hucitec, 2006. p.375-417.

BEMFAM. Sociedade Civil Bem-estar Familiar no Brasil. Pesquisa sobre saúde reprodutiva e sexualidade do jovem: Rio de Janeiro, Curitiba e Recife - 1989/90. Rio de Janeiro: BEMFAM, Centers for Disease Control and Prevention, 1992.

BRASIL. Ministério da Saúde. Coordenação Nacional de DST/AIDS. Manual de redução de danos. Brasília: Ministério da Saúde, 2001a.

Ministério da Saúde. A contribuição dos estudos multicêntricos frente à epidemia de HIV/Aids entre UDI no Brasil: 10 anos de pesquisa e redução de danos. Brasília: Ministério da Saúde, 2001b.

CAIAFFA, W. Projeto AjUDE-BRASIL: avaliação epidemiológica dos usuários de drogas injetáveis dos projetos de redução de danos apoiados pela CN-DST/AIDS. Brasília: Ministério da Saúde, 2001.

CANOLETTI, B.; SOARES, C.B. Programas de prevenção ao consumo de drogas no Brasil: uma análise da produção científica de 1991 a 2001. Interface - Comunic., Saude, Educ., v.9, n.16, p.115-29, 2005. 
CARLINI-COTRIM, B. Drogas na escola: prevenção, tolerância, e pluralidade. In: AQUINO, J.G. (Org.). Drogas na escola: alternativas teóricas e práticas. São Paulo: Summus, 1998. p.19-30.

CARVALHO, M.A.; ACIOLI, S.; STOTZ, E.N. O processo de construção compartilhada do conhecimento: uma experiência de investigação científica do ponto de vista popular. In: VASCONCELOS, E.M. (Org.). A saúde nas palavras e nos gestos: reflexões da Rede de Educação Popular e Saúde. São Paulo: Hucitec, 2001. p.101-14.

CZERESNIA, D. A concepção de saúde e a diferença entre prevenção e promoção. In: CZERESNIA, D.; FREITAS, C.M. (Orgs.). Promoção da saúde: conceitos, reflexões, tendências. Rio de Janeiro: Ed. Fiocruz, 2003. p.39-53.

FEFFERMANN, M.; FIGUEIREDO, R. Uma proposta construtivista para a prevenção ao abuso de drogas. Bol. Inst. Saude, n.40, p.1-10, 2006. Disponível em: <http:// nepaids.vitis.uspnet.usp.br/?page_id=529>. Acesso em: 17 abr. 2008.

FIGUEIREDO, R. Prevenção ao abuso de drogas em ações de saúde e educação: uma abordagem sócio-cultural e de redução de danos. São Paulo: NEPAIDS, 2002.

FREIRE, P. Pedagogia da autonomia: saberes necessários à prática educativa. São Paulo: Paz e Terra, 1996.

FONSECA, E.M. Políticas de redução de danos ao uso de drogas: o contexto internacional e uma análise preliminar dos programas brasileiros. 2005. Dissertação (Mestrado) - Escola Nacional de Saúde Pública, Fundação Oswaldo Cruz, Rio de Janeiro. 2005.

GALDURÓZ, J.C.F. et al. V Levantamento Nacional sobre o consumo de drogas psicotrópicas entre estudantes do ensino fundamental e médio da rede pública de ensino nas 27 capitais brasileiras. São Paulo: Centro Brasileiro de Informação sobre Drogas Psicotrópicas, Universidade Federal de São Paulo, 2004.

GAZZINELLI, M.F. et al. Educação em saúde: conhecimentos, representações sociais e experiências da doença. Cad. Saude Publica, v.21, n.1, p.200-6, 2005.

GEERTZ, C. A interpretação das culturas. Rio de Janeiro: LCT Editora, 1989.

GUERCHMAN, M.L. Breve estudo da perspectiva do adolescente. 1998. Monografia (Especialização) - Pontifícia Universidade Católica do Paraná, Curitiba. 1998.

HILTON, B.A. et al. Harm reduction theories and strategies for control of human immunodeficiency virus: A review of the literature. J. Adv. Nurs., v.33, n.3, p.357-70, 2000.

LARANJO, T.H.M. O CRUSP: processos de socialização e uso de drogas. 2004.

Dissertação (Mestrado) - Escola de Enfermagem, Universidade de São Paulo, São Paulo, 2004.

MARTINI, J.G.; FUREGATO, A.R.F. Representações sociais de professores sobre o uso de drogas em uma escola de ensino básico. Rev. Latino-am. Enferm., v.16, n.esp., p.601-6, 2008.

MINAYO, M.C.S. Desafio do conhecimento: pesquisa qualitativa em saúde. 8.ed. São Paulo: Hucitec, 2007.

MONTEIRO, S. et al. Educação, drogas e saúde: uma experiência com educadores de programas sociais (RJ - Brasil). Rio de Janeiro: LEAS, Instituto Oswaldo Cruz, Fundação Oswaldo Cruz, 2008.

MOREIRA, F.G.; SILVEIRA, D.X.; ANDREOLI, S.B. Redução de danos do uso indevido de drogas no contexto da escola promotora de saúde. Rev. Cienc. Saude Colet., v.11, n.3, p.807-16, 2006. 
PAGLIA, A.; ROOM, R. Preventing substance use problems among youth: a literature review \& recommendations. Addiction Research Foundation Division. Centre for Addiction and Mental Health. Document n.142, Canada, May, 1998. Disponível em: <http://www.google.com.br>. Acesso em: 19 fev. 2009.

PAULILO, M.A.S.; JEOLÁS, L.S. Jovens, drogas, risco e vulnerabilidade: aproximações teóricas. Serv. Soc. Rev., v.3, n.1, p.39-60, 2000.

SANTOS, V.E.; SOARES, C.B.; CAMPOS, C.M.S. Redução de danos: análise das concepções que orientam as práticas no Brasil. Physis, v.20, n.3, p.995-1015, 2010.

SOARES, C.B.; JACOBI, P.R. Adolescentes, drogas e AIDS: avaliação de um programa de prevenção escolar. Cad. Pesqu., n.109, p.213-37, 2000.

SOARES, C.B. et al. Juventude e consumo de drogas: oficinas de instrumentalização de trabalhadores de instituições sociais, na perspectiva da saúde coletiva. Interface Comunic., Saude, Educ., v.13, n.28, p.189-99, 2009.

SOUZA, K.M. Práticas educativas sobre saúde e drogas entre educadores de programas sociais: um estudo qualitativo no estado do Rio de Janeiro. 2010. Dissertação (Mestrado) - Escola Nacional de Saúde Pública Sergio Arouca, Rio de Janeiro. 2010.

VÍCTORA, G.C.; KNAUTH, D.R.; HASSEN, M.N.A. Pesquisa qualitativa em saúde: uma introdução ao tema. Porto Alegre: Tomo Editorial, 2000.

SOUZA, K.M.; MONTEIRO, S. Planteamiento de reducción de daños en espacios educativos no formales: un estudio cualitativo en el estado de Rio de Janeiro, Brasil. Interface - Comunic., Saude, Educ., v.15, n.38, p.833-44, jul./set. 2011.

El artículo discute las contribuiciones del planteamiento de reducción de daños para la práctica educativa en salud y drogas, en espacios no formales, partiendo del análisis de los fundamentos teórico-metodológicos y de las actividades de un proyecto desarollado por el Instituto Oswado Cruz, con educadores de organizaciones no gobernamentales de Rio de Janeiro, de 2006 y 2007. Utilizando un enfoque cualitativo, el estudio ha analizado la trayectoria y las prácticas profesionales de educadores y el contexto institucional, por medio de análisis documental, entrevistas y observación directa. Los hallazgos han revelado que hubo apropiación y resignificación, por parte de los educadores, de los conceptos analizados en el proyecto relativos a la educación para la autonomía, reducción de daños y vulnerabilidad individual, orientados por un planteamiento dialógico y crítico del proceso de construcción del conocimiento.

Palabras clave: Educación en Salud. Drogas. Reducción de Daños. Metodología. Formación de educadores. 